\title{
THE USE OF A COMBINED PORTABLE X RAY FLUORESCENCE AND MULTIVARIATE STATISTICAL METHODS TO ASSESS A VALIDATED MACROSCOPIC ROCK SAMPLES CLASSIFICATION IN AN ORE EXPLORATION SURVEY.
}

Figueroa Cisterna, J. ${ }^{(a)}$; Bagur González, M.G. ${ }^{(\mathbf{b}, \mathbf{c})}(\varangle)$; Morales Ruano, S. ${ }^{(\mathbf{a}, \mathbf{c})}$; Carrillo Rosúa, J.C. ${ }^{(c, d)}$ and Martín Peinado, F. ${ }^{(e)}$

(a) Department of Mineralogy and Petrology, Faculty of Sciences, Avda. Fuentenueva s/n, University of Granada, 18071, Granada, Spain

(b) Department of Analytical Chemistry, Faculty of Sciences, Avda. Fuentenueva s/n, University of Granada, 18071, Granada, Spain.

(c) Instituto Andaluz de Ciencias de la Tierra (University of Granada-CSIC), Faculty of Sciences, Avda. Fuentenueva s/n, University of Granada, 18071, Granada, Spain.

(d) Department of Didactics of Experimental Sciences. Faculty of Education Sciences, Campus de Cartuja s/n, University of Granada, 18071, Granada, Spain.

1 (e) Department of Soil Science, Faculty of Sciences, Avda. Fuentenueva, University of 2 Granada, 18071, Granada, Spain.

4 Keywords: Portable X Ray Fluorescence Analyzer (P-XRF), Box-Cox Transformation, 5 Pattern Recognition Techniques, Ore Exploration, $\mathrm{Cu}-(\mathrm{Ag})$ Deposits.

(ه) Corresponding author: Phone: +34958243327; Fax: +34958243328

e-mail: mgbagur@ugr.es

\section{Postprint versión.}

Original paper: Figueroa-Cisterna, J., Bagur-González, M. G., Morales-Ruano, S., Carrillo-Rosúa, J., \& Martín-Peinado, F. (2011). The use of a combined portable $\mathrm{X}$ ray fluorescence and multivariate statistical methods to assess a validated macroscopic rock samples classification in an ore exploration survey. Talanta, 85(5), 2307-2315. doi:10.1016/j.talanta.2011.07.034 


\section{Abstract}

2

3 The combination of "ex-situ" portable X Ray Fluorescence with unsupervised and

4 supervised pattern recognition techniques such as hierarchical cluster analysis, principal

5 components analysis, factor analysis and linear discriminant analysis have been applied

6 to rock samples, in order to validate a "in situ" macroscopic rock samples classification

7 of samples collected in the Boris Angelo mining area (Central Chile), during a drill-hole

8 survey carried out to evaluate the economic potential of this $\mathrm{Cu}$ deposit. The analysed

9 elements were $\mathrm{Ca}, \mathrm{Cu}, \mathrm{Fe}, \mathrm{K}, \mathrm{Mn}, \mathrm{Pb}, \mathrm{Rb}, \mathrm{Sr}$, Ti and $\mathrm{Zn}$. The statistical treatment of the

10 geological data has been arisen from the application of the Box-Cox transformation

11 used to transform the data set in normal form to minimize the non-normal distribution

12 of the data. From the statistical results obtained it can be concluded that the

13 macroscopic classification applied to the transformed data permits at least, to

14 distinguish quite well in relation to two of the rock classes defined (70.5\% correctly

15 classified $(\mathrm{p}<0.05))$ as well as for four of the five alteration types defined "in situ"

16 (75\% of the total samples). 


\section{Introduction}

2

3

4

The extraction of metals from the earth crust initially requires the identification of the areas in which they have anomalous concentration in relation to the host rock of the ore mineralization and, in general sense, to the background in the mining zone. In this sense, the geological characterization of the potential host rocks of ore mineralization is crucial and must be the preliminary objective in any exploration survey.

In relation with this fact, two fundamental stages must be covered, the establishment of the geological cartography and the drill-hole survey. The former because permits the knowledge of the main geological features (lithologies, structures, mineralization evidences, etc.) and the later because gives an invaluable set of data over the geology under the surface. From the study of the information obtained in these stages it is possible to get a three dimensional idea about the existing rocks and their characteristics. Thus recognition and classification of the different rock types, as well as its alteration pattern, play an important role which could be critic in the selection of the areas that could be adequate to explore host ore bodies with economic interest.

During the initial field campaign necessary in order to obtain the data, a lot of samples are generates. In this sense, they must be classified attending criteria closely related to the type of deposits to be exploited, e.g. type of lithologies, hydrothermal alteration patterns among others. In the most of the cases these criteria are applied "in situ" in remote areas without confirmatory analytical information from a laboratory, and, in the best of the cases, using basic equipment like a magnifying glass or some safe and easily portable chemical reagent. In this way, it could be helpfully to dispose of qualimetric tools that could validate this macroscopic rock samples classification in order to facilitate and accelerated the remained work necessary to determine the goodness of the ulterior mining exploration of the zone investigated.

Bearing in mind these reasons, the use of analytical techniques as portable X-ray fluorescence (P-XRF) combined with statistical pattern recognition techniques can be offered as an adequate tool in order to obtain a feasible model that could permits the 
1 assessment of a validated macroscopic rocks samples classification in an ore exploration survey.

Up to the present day, the use of field portable X-ray fluorescence (P-XRF) analysers [1-5] has been demonstrated be adequate in order to solve questions related with a great variety of deals, e.g. for the assessment of the composition of painting materials in order to offer information about their conservation and/or restoration procedures [6,7], for archaeological studies [8,9], for the screening and assessment studies about metalloids and/or heavy metals in contaminated or potentially contaminated areas $[3,4,10-14]$, FDA regulated products [15], or metal contents in waters [16], among others. On the other hand, the relatively low cost of these devices permits the possibility of their use in lab for routine analysis in quality control assessments.

In parallel, it has been demonstrated that the use of unsupervised and supervised pattern recognition techniques permits to extract reliable information from analytical parameters for exploratory assessment of geological sets [17-19], mainly due to they allow (a) to verify associations among variables, (b) to group or to cluster samples with respect to comparable chemical or geological descriptors, and (c) to search multivariate data classification on the basis of known class membership of those objects.

Nowadays, copper is one of the most demanded materials on the metal market showing a growing demand perspective at the present such as the future. Together with this growing demand, the exploration of this metal has been widespread for the entire world to satisfy the copper supply. In this context, Chile is the first copper-producing country holding a $36 \%$ of the world production of this metal.

Boris Angelo $\mathrm{Cu}-(\mathrm{Ag})$ deposit is located in the "stratabound $\mathrm{Cu}-(\mathrm{Ag})$ belt" [20] in the Costal Cordillera, Central Chile. It corresponds to practically unknown deposit in this belt, thus the study carried out in the area can be considered as a typical case study of an exploration survey of a copper deposit. In this paper, a normalized data matrix obtained from P-XRF measurements of rocks samples from a "preliminary ore exploratory survey" has been subjected to different pattern recognition techniques in 
1 order to confirm the rock classification parameters of samples taken during the drill-

2 hole survey made in the Boris Angelo area.

3

4 2. Material and Methods

5

6

\subsection{Studied area and macroscopic classification defined}

7

The Boris Angelo $\mathrm{Cu}-(\mathrm{Ag})$ deposit is located in the easternmost Coastal Cordillera, in Central Chile, between $32^{\circ} 30^{\prime} \mathrm{S}$ and $70^{\circ} 40^{\prime}$ 'W (Fig. 1). It is part of the Cretaceous stratabound $\mathrm{Cu}-(\mathrm{Ag})$ deposits belt, which are also known as "Chilean Manto-type" $\mathrm{Cu}-(\mathrm{Ag})$ deposits. The geology of the deposit area is characterized by volcanoclastics sequences intruded by different small subvolcanic bodies. Table I shows the four different lithologies recognized in the zone and its most representative characteristics. As well as, the Table 1 included the coded values assigned to them in the macroscopic classification made "in situ".

\section{FIGURE 1}

\section{TABLE 1}

From the point of view of the alteration patterns, the area of the metallic deposit is affected by hydrothermal alteration, caused by the interaction between hot and slightly acidic fluids and the host rocks [21]. These fluids can leach metals (with economic interest) and re-concentrate them. As mentioned above, the recognition and cartography of alteration patters in the rocks is a useful tool used by exploration geologist as evidence to localize enriched-metals areas with economic potential. The most common classification method, and the simplest visual method too, is that which defined the type of alteration as a function of the most abundant or most obvious mineral in the altered rock. Table I shows the five different hydrothermal alterations recognized in the zone, on the basis of the occurrence of certain "key minerals" or "key mineral assemblages" product of the hydrothermal alteration, and its most representative characteristics. In order to facilitate the analysis of the data, a second numerical code has been assigned to the alteration types used in the study. These codes have also been included in Table 1. 


\subsection{Sampling preparation and measurement}

During the field campaign 44 rocks samples, corresponding to ore grade zones and barren zones, were taken from five different drill-hole cores selected (see Figure 1). The samples were coded and placed into sealed plastic bags in order to their preservation and transportation to the "Minera Las Cenizas S.A." mining facilities where they were powdered (until $<100$ microns particle size) and homogenised using standard procedures before their transportation to the laboratory.

The monitored parameters were the concentration of $\mathrm{Ca}, \mathrm{Cu}, \mathrm{Fe}, \mathrm{K}, \mathrm{Mn}, \mathrm{Pb}, \mathrm{Rb}$, $\mathrm{Sr}$, $\mathrm{Ti}$ and $\mathrm{Zn}$. The measurements were made in the laboratory to select the better measure conditions; the equipment used in this study was a field portable X-ray fluorescence analyser NITON XLt 792 (Niton, Billerica, USA), with a $40 \mathrm{kV}$ X-ray tube with Ag anode target excitation source and a Silicon PIN-diode with a Peltier cooled detector. As part of the standard set-up routine, variables as type of holder (zip sealed plastic bag or polyethylene sample cups with Mylar X-Ray Fil (TF-160-255; Gauge $0.00024 "-6 \mu \mathrm{m}, 2.5$ ' diameter) obtained from the supplier, source count time (60, 90 and 120 s) and matrix effects among others were tested.

In relation to the holder to be used in the procedure, the influence of the type of material used was studied analysing a set of 15 holders for each type of containers without sample. No statistical differences $(\mathrm{P}=0.95)$ were found between the holders supplied by NITON and the plastic bags used in the exploratory survey to storage the samples. In all the cases, the content of the elements were lower than those expected in the samples, not being necessary to used the average element content to correct the measurements. For ulterior analysis the zip sealed plastic bags were chosen.

In relation with the influence of the source count time the best results were obtained using 90s. These variables were then kept fixed for the rest of measurements. 31 On the other hand, no matrix effect was detected using the program algorithm included in the analyser software. The analyser was calibrated using the silver and tungsten shielding on the inside shutter. After data acquisition, the results were downloaded to a

34 portable PC for further processing. The results obtained for the rocks samples analysed 
1 (expressed as the arithmetic means of five replicates of each sample) are shown in Table 22

3

4

\section{TABLE 2}

The RPD found for each measured element in the five replicated analysis of the samples has been: 5,9 $<\operatorname{RPD}_{\mathrm{Ca}}<7,8 ; 6,9<\mathrm{RPD}_{\mathrm{Cu}}<9,9 ; 5,8<\mathrm{RPD}_{\mathrm{Fe}}<9,2 ; 7,1<$ $\mathrm{RDP}_{\mathrm{K}}<9,5 ; 9,2<\mathrm{RPD}_{\mathrm{Mn}}<11,9 ; 12,6<\mathrm{RPD}_{\mathrm{Pb}}<15,2 ; 13,9<\mathrm{RPD}_{\mathrm{Rb}}<15,1 ; 7,8<$ $\mathrm{RPD}_{\mathrm{Sr}}<9,9 ; 6,9<\mathrm{RPD}_{\mathrm{Ti}}<9,3 ; 13,1<\mathrm{RPD}_{\mathrm{Ca}}<15,0$.

The accuracy of the method for all the elements except $\mathrm{Rb}$, was corroborated analysing nine replicates of two Certified Materials: CRM052-050 (RT Corporation, Salisbury, United Kingdom) and RTS-1 (Canadian Certified Reference Methods Project, CANMET, Ottawa, Canada). According to the US EPA Method 6200 recommendations for soil samples [22], the accuracy was estimated by the relative percent difference (RPD) between the concentration in the reference material and the concentration measured (expressed as arithmetic mean of the nine replicates) by P-XRF, in all the cases results were in good agreement with the quality US EPA Method (RPD $<10$ for $\mathrm{Cu}, \mathrm{Fe}, \mathrm{Mn}$, Ti and $\mathrm{Zn}, 10<\mathrm{RPD}<25$ for the rest of the elements).

The establishment of the accuracy in the determination of $\mathrm{Rb}$ was made by means of an "in house validation protocol". Thus, three sets of spiked matrix matched samples (nine replicates) containing known Rb concentrations (one level for each set of spiked samples) were measured. The RPD estimated was 12, which is in good agreement with those obtained for the rest of the elements.

The precision was estimated as intermediate precision by the relative percentage deviation percentage (RPD) of the nine measurements of each reference materials or spiked-matrix samples for Rb. In all the cases the obtained RPD values are lesser than 15. In order to estimate the detection limits sets of nine replicate samples that contained the target elements at concentration levels close to the detection limit estimated by US EPA Method 6200 [22]. 
Figure 2 shows the statistical procedure used to the data treatment. Initially, to check the fit of the data to a normal distribution, Kolmogorov-Smirnov, Shapiro-Wilks and skewness score normality tests were applied. In all the cases, statistical evidences at $95 \%$ confidence interval showed that not all variables are normally distributed.

6

\section{FIGURE 2}

In order to transform the data set into normal form, Box-Cox transformation was used [17, 23-25]. To study the correlation structure between normalized variables the Spearman rank-order correlations (Spearman $\mathrm{R}$ coefficient) were used, due to the samples are less sensitive to outliers than the Pearson coefficients.

In all the cases, the univariate and multivariate statistical treatment of the data was performed using: (a) Statgraphic Centurion XV (15.2.05 version) for Windows (Statpoint Technologies Inc, Warrenton, USA) and Matlab Version 7.0.4 R14 (The Mathworks, Inc.) and the PLS Toobox Version 3.0.4 (eigenvector Research, Inc.)..

\subsection{Unsupervised pattern recognition methods: Cluster Analysis (HCA), Principal} Component (PCA) and Factor Analysis (FA)

Hierarchical agglomerative HCA was performed on the normalized data set by means of Manhattan (city-block) distance -a particular case of Minkowski distance (taxicab geometry)- as similarity measurement and Ward's method as amalgamation rule. These criterions have been selected with two objectives: (i) to find at each stage those two clusters whose merger gives the minimum increase in the total within group error sum of squares (Ward objective) and, (ii) to dampen the effect of outliers bearing in mind using city-block distance the average differences across dimensions are not squares. It was applied to the Box-Cox transformed monitoring matrix data set in order to observe the relationship between natural grouping observed and the two criteria of macroscopic classification made (lithologies and alteration patterns). On the other hand in order to verify the natural grouping obtained in HCA, a PCA was applied to the standardized normalized data set. Finally, to reduce the interdependence of the data set 
1 of standardized normalized variables and to obtain knowledge of the underlying 2 structure of the data, FA was applied. In this case the factorization type used was a 3 principal component which supposes that all of the variability of the data corresponds 4 exclusively to common factors. The orthogonal rotation of the axis defined by PCA, and 5 obtained maximizing (Varimax rotation) produces new groups of variables called 6 varifactors (VFs), which usually group the studied variables in accordance with 7 common features which can include unobservable, hypothetical and/or latent variables 8 [26].

\subsection{Supervised pattern recognition methods: Linear Discriminant Analysis (LDA)}

This method has been applied in order to obtain a discriminant model that permits us validated the "in situ" macroscopic rock samples classification of the sample assuming the number of groups or classes, as well as, the group membership of each sample taken. Thus, by means of linear discriminant analysis, a discriminant function has been built up for each group on raw data. The classification functions associated to each group defined could be used to determine to which group each sample most likely belongs. In this study, LDA were performed on the Box-Cox transformed measured data.

\section{Results and discussion}

\subsection{Macroscopic classification made on the basis of lithology criteria.}

The Dendogram resulting from HCA of normalized data set is represented in

26 Figure 3 . It can be seen that assuming a $\mathrm{D}_{\text {linkage }}=0.8 \mathrm{D}_{\text {maximum, }}$, the samples could be grouped in two different clusters: (i) Cluster I, constituted by $29.7 \%$ of the samples. 28 According the rock codes, it contents samples of the four defined lithologies. From 29 which, there are included $100 \%$ of the rocks samples defined like porphyritic dykes 30 (rock code 11) and brecciated porphyritic sub-volcanic rocks (rock code 13). (ii) Cluster 31 II, constituted by the $70.3 \%$ of the samples, it can be observed that it is characterized by the biggest city-block distance (high significant clustering). Belonging to this cluster it

33 can be found $93.5 \%$ rocks samples defined as porphyritic sub-volcanic rocks (rock code

34 12) and $40 \%$ of the samples defined as volcanoclastic rocks (rock code 14 ). 


\section{FIGURE 3}

3

4

The PCA (made on the basis of eigenvalues $>1$ criterion) facilitated the explanation of the original 10 geochemical variables in a reduced space by three sets of the calculated principal components (PCs) which explaining about $73.9 \%$ of the total variance. The analysis of the data (see Table 3(a)) shows that PC1 (41.6\% of the total variance) is mainly influenced positively by the normalized concentration of $\mathrm{Ca}, \mathrm{Sr}$ and $\mathrm{Ti}$, and negatively by the normalized concentration of $\mathrm{K}$ and Rb. PC2 (19.9\% of the total variance) is manly influenced positively by the normalized concentration of $\mathrm{Fe}$, $\mathrm{Mn}$ and $\mathrm{Zn}$, and PC3 (which explains the 12.4\% of the total variance) influenced positively by $\mathrm{Pb}, \mathrm{Zn}$ and $\mathrm{Cu}$.

On the other hand, from the scattered plot obtained, considering PC1 and PC2 (Figure 4(a)) two group of samples (A and B) can be observed. Group A is mainly characterized by negative values of the PC1 and PC2 whereas Group B is characterized by positive values of the PC1. In relation to the samples lithological classification made, Group A is formed by one lithology class, i.e. porphyritic sub-volcanic rocks and contents $93.5 \%$ of all of the samples coded as 12 . Group B, more heterogeneous than the one, collects $100 \%$ of the samples classified as porphyritic dykes (rock code 11), brecciated porphyritic sub-volcanic (rock code 13) and volcanoclastic rocks (rock code 14), as well as two samples coded as rock code 12.

\section{FIGURE 4}

In relation with the previous HCA it can be observed that, although the natural behaviour of the samples is quite similar, the lineal combination of the normalized values of concentrations of the elements made by PCA permit us the grouping of the samples into two groups well defined: Group A, constituted by porphyritic sub-volcanic rocks and Group B, constituted mainly for the rest of the lithologies classes. 
When the FA was applied, the Varimax rotation of the axes defined by the PCs explains again about $73.9 \%$ of the total variance of the normalized data, but modify the weight of the normalized variables in the three varifactors (VFs) obtained by means of the eigenfactor $>1$ criterion (see Table 3(b)). The scattered plot of the first two varifactors is shown in Figure 5(a). It can be observed again two different groups of rock samples (A and B) which can be considered as identical as those obtained by PCA.

\section{FIGURE 5}

In general, the unsupervised pattern recognition methods applied to the Box-Cox transformed concentrations of the analysed elements by P-XRF permit asses that in all cases $61.4 \%$ of the samples are "naturally" grouped as belonging to the macroscopic group named porphyritic sub-volcanic rocks (rock code 12). The samples macroscopically classified as porphyritic dykes and brecciated porphyritic sub-volcanic rocks (rock codes 11 and 13 respectively) present a slightly defined patter of distribution between them (Fig. 4). The dispersion shown by rocks classified like volcanoclastics rocks (14) could be attributed to the compositional heterogeneity characteristics of them.

In order to verify the natural grouping obtained and to validate the macroscopic classification, by means a statistical significant driscriminant model, a LDA was performed. The discriminant functions were calculated considering the Box-Cox normalized metals concentrations that mainly affect to VF1. On these bases, i.e. WCa, $\mathrm{WFe}, \mathrm{WK}, \mathrm{WRb}, \mathrm{WSr}$ and WTi, three discriminant orthogonal functions were calculated. DF1 and DF2 contribute $99.20 \%$ to the total discriminant power being both functions statistically significant at 95\% percentage. Eq. 1 and 2 represent the expression of these functions.

$\mathrm{DF} 1_{\text {lithol. }}=-0.9 \mathrm{WK}+-0.4 \mathrm{WCa}+0.2 \mathrm{WFe}+0.5 \mathrm{WRb}+0.6 \mathrm{WSr}+0.8 \mathrm{WTi}$

$\mathrm{DF} 2_{\text {lithol. }}=-0.9 \mathrm{WK}-0.1 \mathrm{WFe}+1.6 \mathrm{WRb}+0.6 \mathrm{WSr}-0.2 \mathrm{WTi}$

In order to evaluate the adequation of the classification model obtained, the samples were split into six groups and two levels for a 6-fold cross validation inner group by 
1 means of Venetian blinds. The percentages of variance captured by the model were $272.80 \%$. Figure 6(a) shows the scatter plots of observations in the space of discriminant 3 functions.

\section{FIGURE 6}

6

Table 4(a) shows the classification percentages obtained from each class macroscopically defined. It can be observed that the predicted model with DF1 and

9 DF2, considering the normalized geochemical information obtained with P-XRF measurements, classify satisfactory the $70.45 \%$ of the data. These facts could be closely related to (i) the heterogeneous composition of the "volcanoclastics rocks" (rock code 14), (ii) The similarity of the original composition between the "brecciated porphyritic sub-volcanic rocks (rock code 13)" and "porphyritic sub-volcanic rocks (rock code 12)", as well as the matrix composition of the first rock type, (iii) the state of aggregation (powdered particles with $<2 \mathrm{~mm}$ ) in which the samples are measured that does not permit to appreciate the brecciated structure.

\section{TABLE 4}

\subsection{Macroscopic classification made on the basis of hydrothermal alteration criteria}

In relation with the macroscopic classification made on basis of hydrothermal alteration criteria, from the analysis of the Dendogram (see Figure 3) can be observed that, in this occasion Cluster I is also the most heterogeneous. It is constituted by $56.25 \%$ of samples coded as propylitic alteration (alteration code 21 ), $100 \%$ of samples classified as "chloritic alteration" and "carbonatization" (alteration codes 25 and 22) and $50 \%$ of samples coded as "argillic assemblages" (alteration code 24). Whereas

29 Cluster II is constituted by $100 \%$ of samples macroscopically defined as "albitic 30 alteration" (alteration code 23), 50\% of samples defined as "argillic assemblages" 31 (alteration code 24 ) and by $43.75 \%$ of samples defined like propylitic assemblages 32 (alteration code 21). 
The results arisen from PCA (see Figure 4(b)) permit us consider again two

2 groups: Group A constituted by $100 \%$ of samples as "albitic alteration" (alteration code

323 ), 45.45\% of rock samples assigned as "propylitic alteration (alteration code 21) and

$450 \%$ of rock samples assigned as "argillic assemblages" (alteration code 24). Whereas,

5 Group B includes $68.75 \%$ of samples assigned to "propylitic alteration" (alteration code

$621)$, as well as samples defined as carbonatization (100\%), argillic assemblages (50\%)

7 and chloritic (100\%) alterations respectively.

8

In relation with the information obtain from FA, the scattered plot of the first two varifactors is shown in Figure 5(b). It can be observed again two different groups of rock samples (A and B) which can be defined as those obtained by PCA. Thus, Group A is mainly constituted by $100 \%$ of "albitic alteration" (alteration code 23), meanwhile Group B is mainly constituted by samples belonging to "propylitic alteration" (alteration code 21) most of them characterized by high values of VF1 and VF2 and widespread distributed.

On the other hand, VF1 could be considered in close relation with alteration process, because most of the elements with highest weight, i.e. $\mathrm{Ca}, \mathrm{K}, \mathrm{Rb}$ and $\mathrm{Sr}$ could be involved in hydrothermal process [21]. These facts are in good agreement with positive influence of $\mathrm{WCa}, \mathrm{WSr}$ and $\mathrm{WTi}$, and negative influence of $\mathrm{WK}$ and $\mathrm{WRb}$ in VF1 found in Group B, constituted by samples with propylitic assemblages and chloritic and carbonatization alterations. Additionally, this is too concordant with the mineralogy (possibly unaltered plagioclase like main mineral phase) of porphyritic (andesitic) dykes. The effect of Ti could be attributed to the presence of ilmenite in the ground mass of dykes. The samples classified as "albitic alteration" has a higher negative influence of $\mathrm{WK}$ and $\mathrm{WRb}$, this fact could be due to $\mathrm{Na}$ widespread replacement involved in the plagioclase albitization process. This last mineral could be constituted (as initial composition) by significant amounts of $\mathrm{K}$ an $\mathrm{Rb}$ in its structure.

VF2 is influenced by the normalized concentrations of base metals as Mn and $\mathrm{Zn}$, while VF3 are influenced by $\mathrm{Cu}$ and $\mathrm{Pb}$. These elements could be related with ore mineralization process, nevertheless all the samples show a similar scattered distribution pattern in the diagrams without significance statistical differences inter samples. 
Finally, in order to obtain a feasible classification model a PLS-LDA was made.

2 In this case, considering geochemical features i.e. (a) elements closely related to 3 hydrothermal alterations, i.e. WCa, WK, WRb, WSr and (b) the element with 4 economical interest, $\mathrm{WCu}$. On these bases, four discriminant orthogonal functions were calculated. DF1 and DF2 contribute $89.13 \%$ to the total discriminant power being both

6 functions the most statistically significant at 95\% percentage. Eq. 3 and 4 show the 7 expressions of these functions,

8

$\mathrm{DF} 1_{\text {alt }}=0,6 \mathrm{WCa}-1,1 \mathrm{WK}+\mathrm{WRb}+0.3 \mathrm{WSr}-0.5 \mathrm{WCu}$

$\mathrm{DF} 2_{\mathrm{alt}}=\mathrm{WCa}+0.8 \mathrm{WK}-0.2 \mathrm{WRb}-0.6 \mathrm{WSr}-0.1 \mathrm{WCu}$

10 On the other hand, in order to evaluate the adequation of the classification model 11 obtained, the samples were split into six groups and two levels for a 6-fold cross 12 validation inner group by means of Venetian blinds. For this stage the analyses were 13 performed the percentages of variance captured by the model were $72.80 \%$ for 14 lithology and $73.32 \%$ for alteration. Figure 5(b) shows the scatter plots of observations in the space of discriminant functions.

Table 4(b) shows the classification percentages obtained from each type of alteration macroscopically considered. It can be observed that the predicted model considering (i) geological features and (ii) chemical information obtained with P-XRF measurement classify satisfactory the $75 \%$ of the data. The heterogeneity in the predicted types obtained for the samples assigned to "propylitic alteration" could be attributed to the fact that this kind of alteration could content, at micro-scale level, small bodies corresponding to a different alteration process (e.g. carbonatization, chloritic, etc.) not detectable with the equipment used in field campaign sampling.

\section{Conclusions}

The statistical treatment of the Box-Cox transformed geological data obtained from "ex-situ” portable X Ray Fluorescence measurements of ore exploratory samples with unsupervised and supervised pattern recognition techniques such as HCA, PCA, FA and LDA has been shown as a helpfully tool for validate the "in-situ" macroscopic 
1 rock samples classification applied to an exploratory survey in a potential mining area.

2 From the DLA it can be concluded that in relation with the macroscopic rock samples 3 classification based on lithology classes assuming a probability level of $80 \%$ the 4 discriminant model obtained confirms correctly $81.8 \%$ of the analyzed samples. When

5 the alteration types are considered, the discriminant model obtained permits to confirm

6 four of the five alteration types defined "in situ" (75\% of the total samples). Thus, it can

7 be pointed out that the classification assessed could be applied to facilitate and

8 accelerated the remained work necessary to determine the goodness of the ulterior 9 mining exploration.

11 On the other hand, the proposed approach could be apply directly "in situ" without pre12 treatment of the rocks samples during exploratory in those cases in which the 13 characteristic of the samples could be well assessed.

\section{Acknowledgments}

This work was supported by the Spanish project CGL-2006-02594-BTE 19 (founded by Ministry of Science and Innovation = Ministry of Education and Science 20 and Fondo Europeo de Desarrollo Regional, FEDER). The authors are grateful to 21 Minera Las Cenizas S.A. (Cabildo, Chile) for its help during field work and also thanks 22 for the providing access to geological and geochemical information of the studied area. 
3 [1] S. Piorek, Trends in Analytical Chemistry 13 (1994), 281-285.

4 [2] A. Argyraki, M. H. Ramsey, P. J. Potts, Analyst (1997), 122, 743-749.

5 [3] P. J. Potts, M. H. Ramsey, J. Carlisle, Journal of Environmental Monitoring 4 6 (2002), 1017-1024.

7 [4] J. Chou, G. Clement, B. Bursavich, D. Elbers, B. Cao, W. Zhou, Environmental 8 Pollution 158 (2010), 2230-2234.

9 [5] P.J. Potts, in J. Potts and M. West (Eds.), Portable X-ray Fluorescence 10 Spectrometry: Capabilities for in-situ analysis, RSC Publishing, London (2008), pp 11112.

12 [6] F. Rosi, A. Burnstock, K. J. Van den Berg, C. Miliani, B. G. Brunetti A. Sgamellotti, 13 Spectrochimica Acta Part A: Molecular and Biomolecular Spectroscopy 71 (2009), $14 \quad 1655-1662$.

15 [7] G. Van der Snickt, K. Janssens, O. Schalm, C. Aib'eo, H. Kloust, M. Alfelda, X-Ray 16 Spectrom. 39 (2010), 103-111.

17 [8] S. C. Phillips, R. J. Speakman, Journal of Archaeological Science 36 (2009), 1256181263.

19 [9] A. J. Nazaroff, K. M. Prufer, B.L. Drake, Journal of Archaeological Science 37 20 (2010) 885-895.

21 [10] P. L. Drake, N. J. Lawryk, K. Ashley, A. L. Sussell, K. J. Hazelwood, R. Song, 22 Journal of Hazardous Materials 102 (2003) 29-38.

23 [11] C. Kilbride, J. Poole, T.R. Hutchings, Environmental Pollution 143 (2006) 16-23.

24 [12] T. Radu, D. Diamond, Journal of Hazardous Materials 171 (2009) 1168-1171.

25 [13] K. Hürkamp,T. Raab, J. Völkel, Geomorphology 110 (2009) 28-36.

26 [14] M. Ramsey, in J. Potts and M. West (Eds.), Portable X-ray Fluorescence 27 Spectrometry: Capabilities for in-situ analysis, RSC Publishing, London (2008), pp 392855.

29 [15] P. T. Palmer, R. Jacobs, P. E. Baker, K. Ferguson, S. Webber, Journal of 30 Agricultural and Food Chemistry 57 (2009), 2605-2613.

31 [16] F.L. Melquiades, P.S. Parreira, M.J. Yabe, M.Z. Corazza, R. Funfas, C.R. 32 Appoloni, Talanta 73 (2007) 121-126.

33 [17] M. G. Bagur, S. Morales, M. López-Chicano Talanta, 80 (2009), 377-384. 
1 [18] F. Martín-Peinado, S. Morales-Ruano, M. G. Bagur-González, C. Estepa-Molina, 2 Geoderma 159 (2010), 76-82.

3 [19] M.G. Bagur-González, C. Estepa-Molina, F. Martín-Peinado, S. Morales-Ruano, 4 Journal of Soils and Sediments. DOI: 10.1007/s11368-010-0285-4 (On line from $509 / 2010)$.

6 [20] V. Maksaev, M. Zentilli, Chilean Strata-bound Cu-(Ag) Deposits: An Overview, in 7 Porter, T.M. (Ed.), Hydrothermal Iron Oxide Copper-Gold \& Related Deposits: A 8 Global Perspective, PGC Publishing, Adelaide 2(2002), pp 185-205.

9 [21] H. L. Barnes, Geochemistry of Hydrothermal Ore Deposits, third ed., Wiley, John 10 \& Sons, 1997.

11 [22] U.S. EPA, 2006. XRF technologies for measuring trace elements in soil and 12 sediment. Niton XLt 700 Series XRF Analyzer. Innovative technology verification 13 report EPA/540/R-06/004.

14 [23] G.E.P. Box, D.R. Cox, Royal Statistical Association, B26 (1964) 211-250

15 [24] M. Meloun, J. Militký, M. Forina, in PC-Aided Statistical Data Analysis vol. 1 16 (1992) Ellis Horwood, Chichester, United Kingdom.

17 [25] M. Meloun, M. Sâňka, P. Němec, S. Krĭtikova, K. Kupta, Environmental Pollution $18137(2005)$ 273-280

19 [26] C. Pérez-López in Estadística Práctica con STATGRAPHICS, Pearson Education 20 S.A. (2002), Madrid, Spain. 


\section{FIGURE CAPTIONS}

2

3 Figure 1. Geological map of the Boris Angelo area. 1. Porphyritic dykes $2 \& 3$.

4 Brecciated porphyritic sub-volcanic rocks 4. Porphyritic sub-volcanic rocks 5.

5 Volcanoclastics rocks 6. Fault 7. Mineralized vein-fault 8. Contact 9. Drill-hole A, B, C

6 and D. Cross section showing the drill holes position and samples location.

7

8 Figure 2. Scheme of the statistical procedure used for data treatment.

9

10 Figure 3. Dendogram resulting from HCA of the Box-Cox normalized data set (R: rock 11 code; A: alteration code; S: sample).

13 Figure 4. Scatterplots obtained from PCA of the Box-Cox normalized data set using: 14 (a) rock codes and (b) alteration codes.

16 Figure 5. Scatterplots obtained from FA of the Box-Cox normalized data set using (a) 17 rock codes and (b) alteration codes.

19 Figure 6. Scatterplots obtained from Discriminant Functions of the Box-Cox 20 normalized data set using (a) rock codes and (b) alteration codes. 

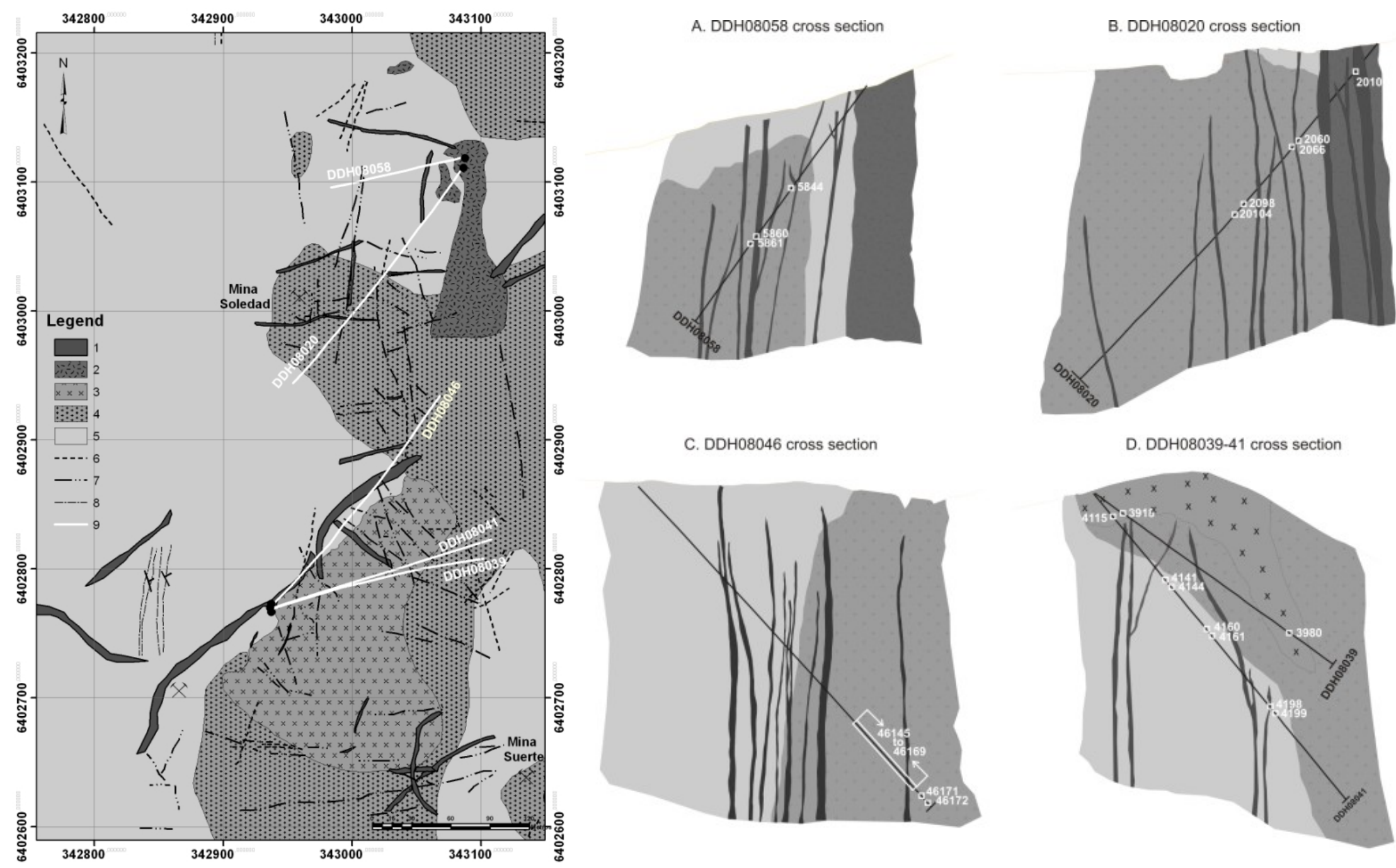

D. DDH08039-41 cross section

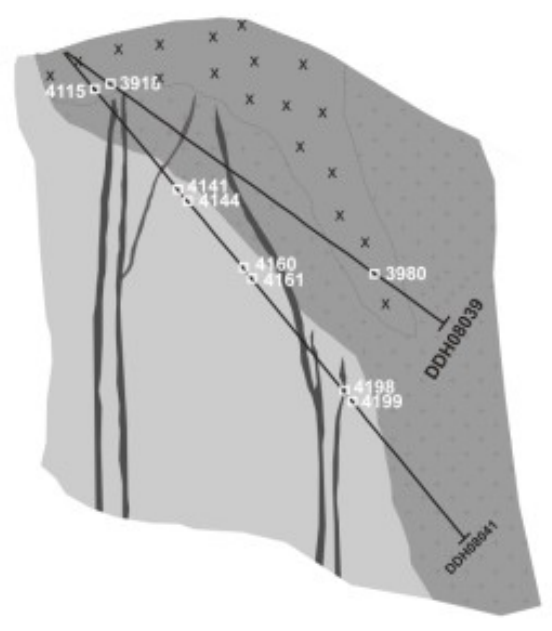

Figure 1 


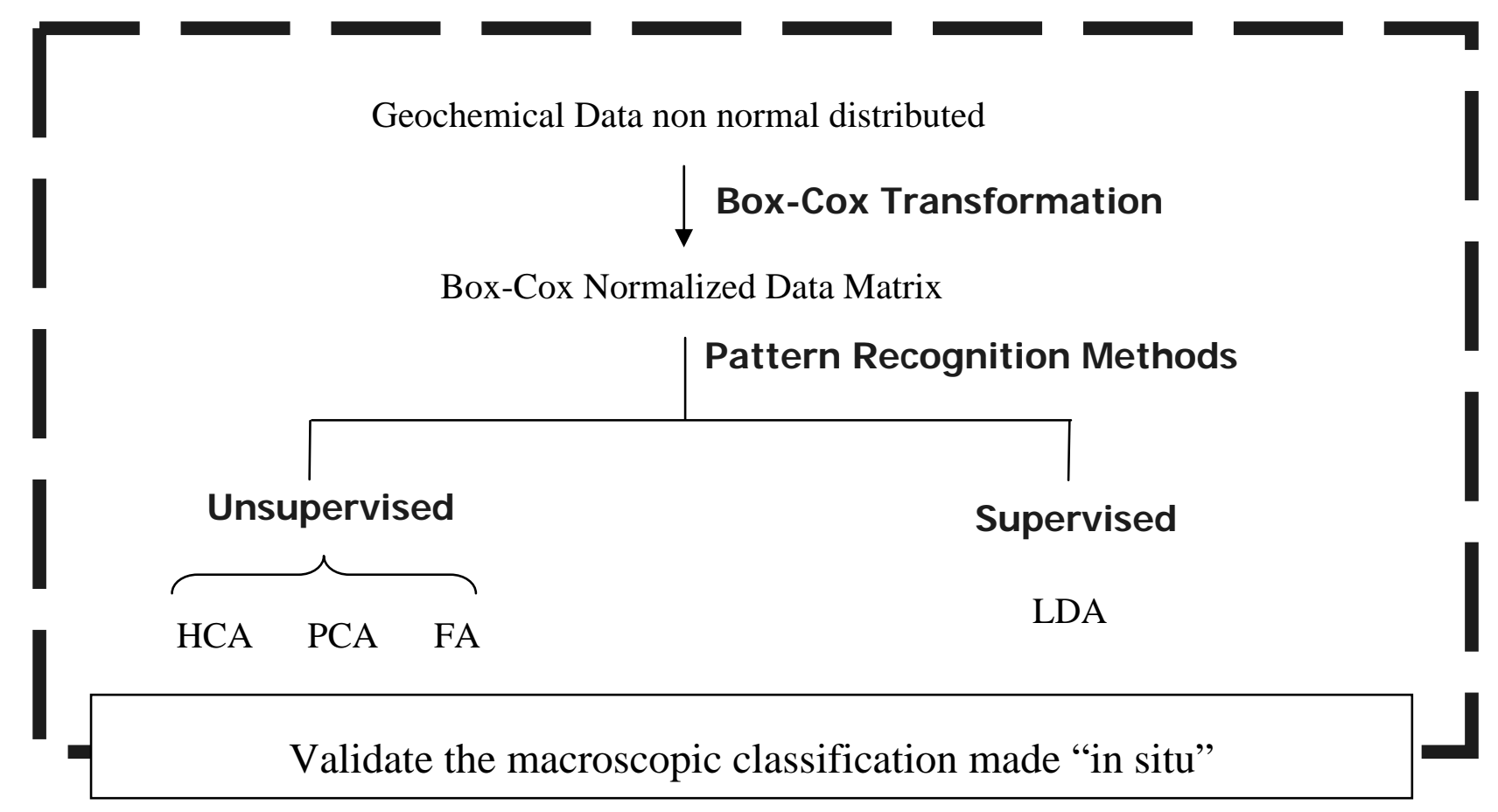

Figure 2 


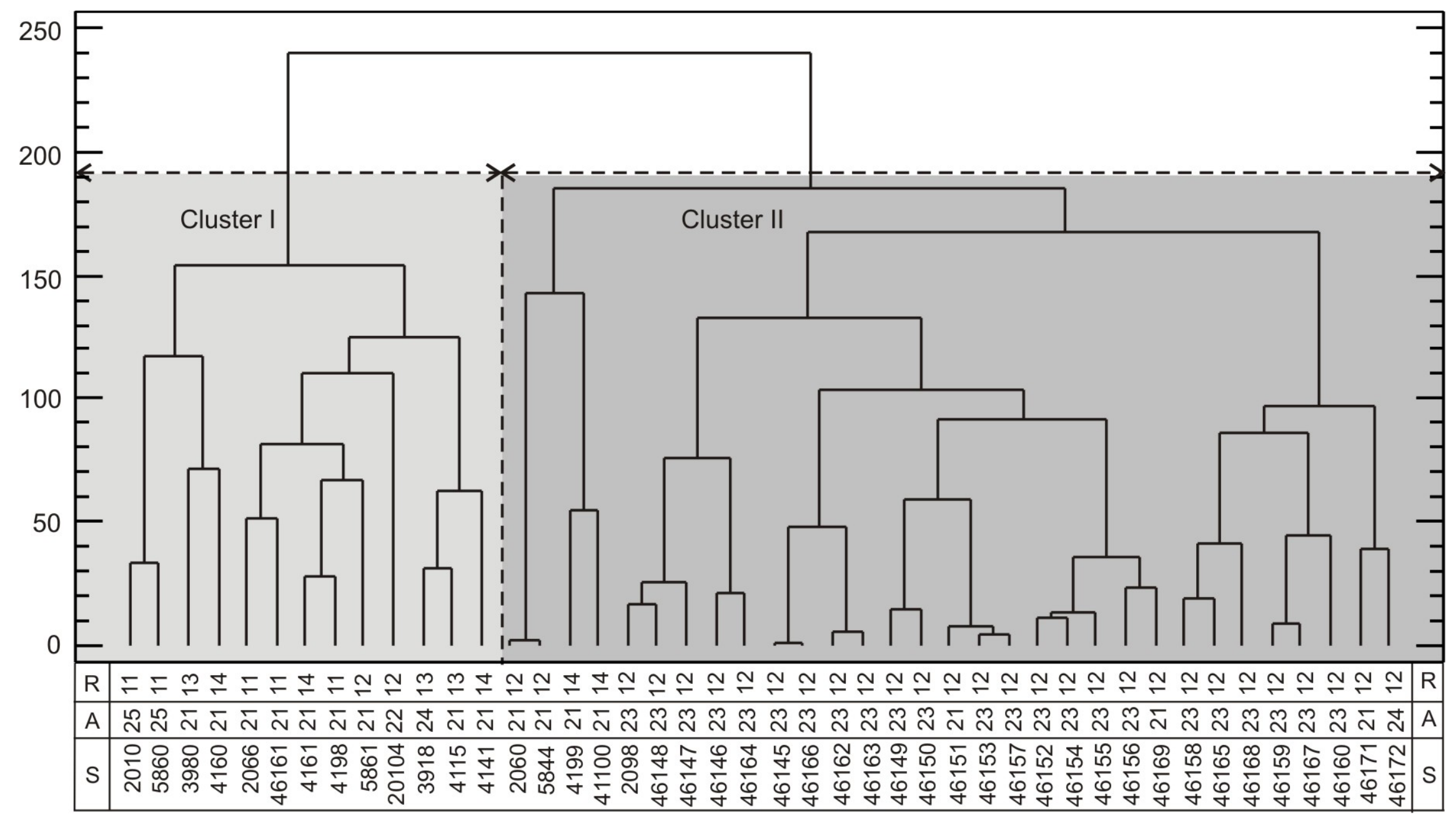

Figure 3 


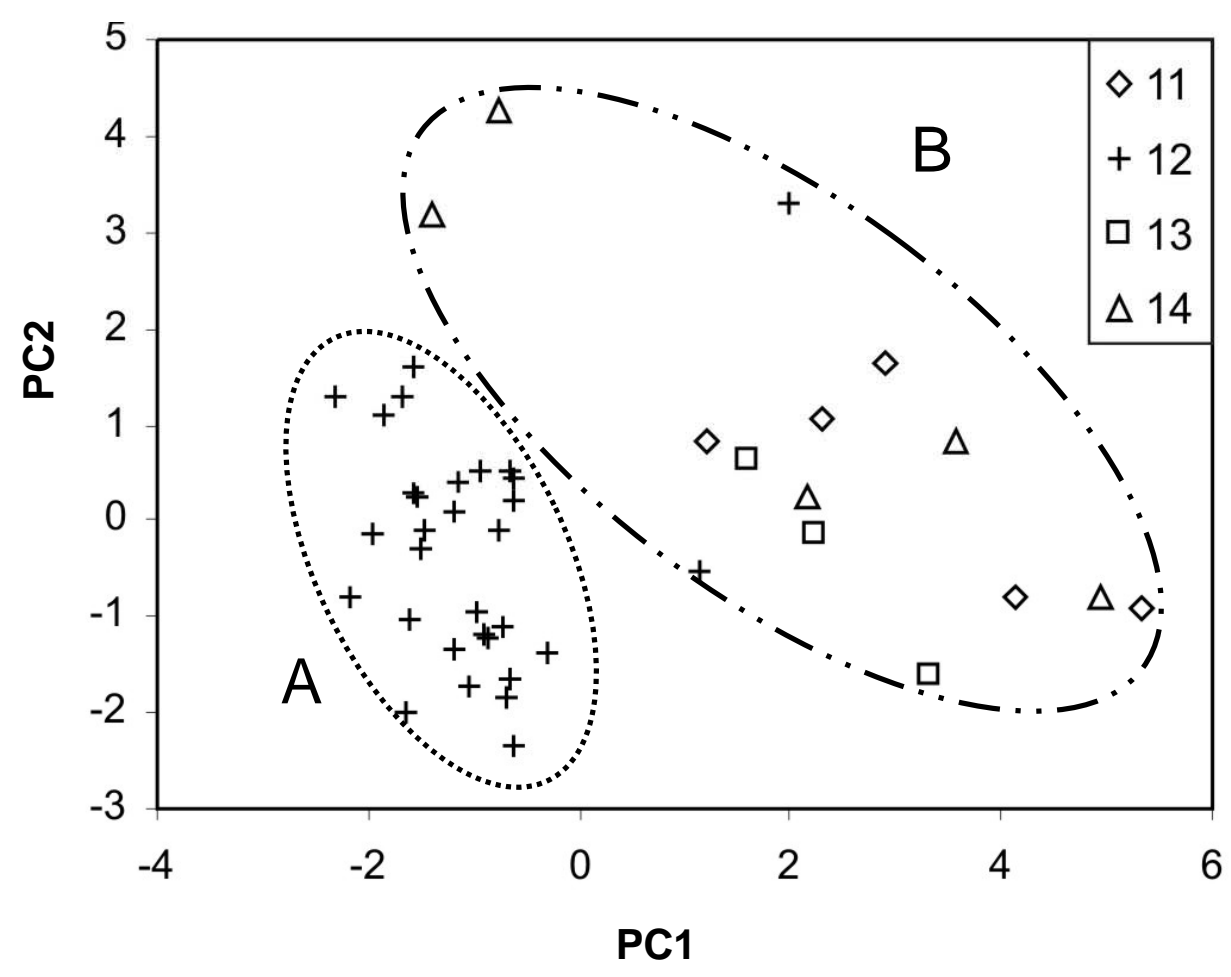

(A)

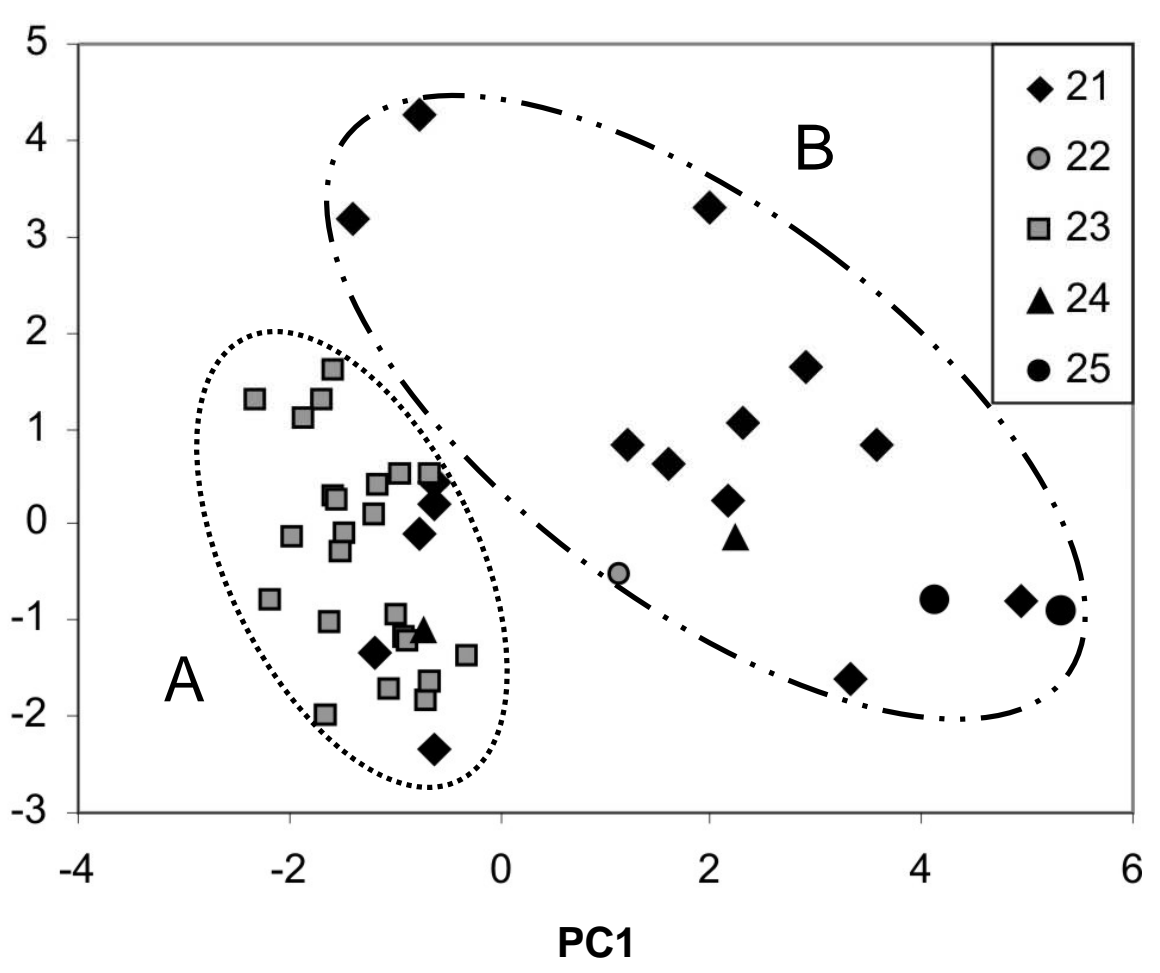

(B)

Figure 4 


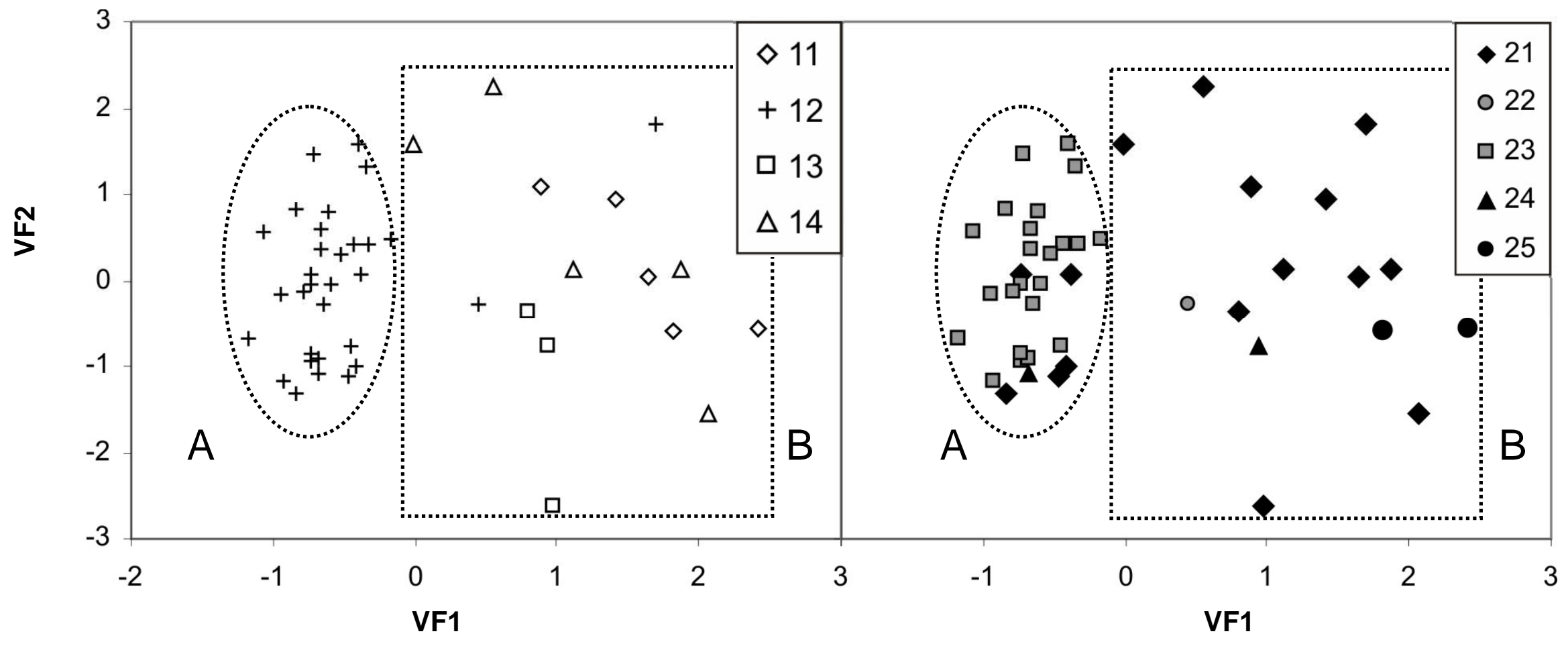

(A)

(B)

Figure 5 

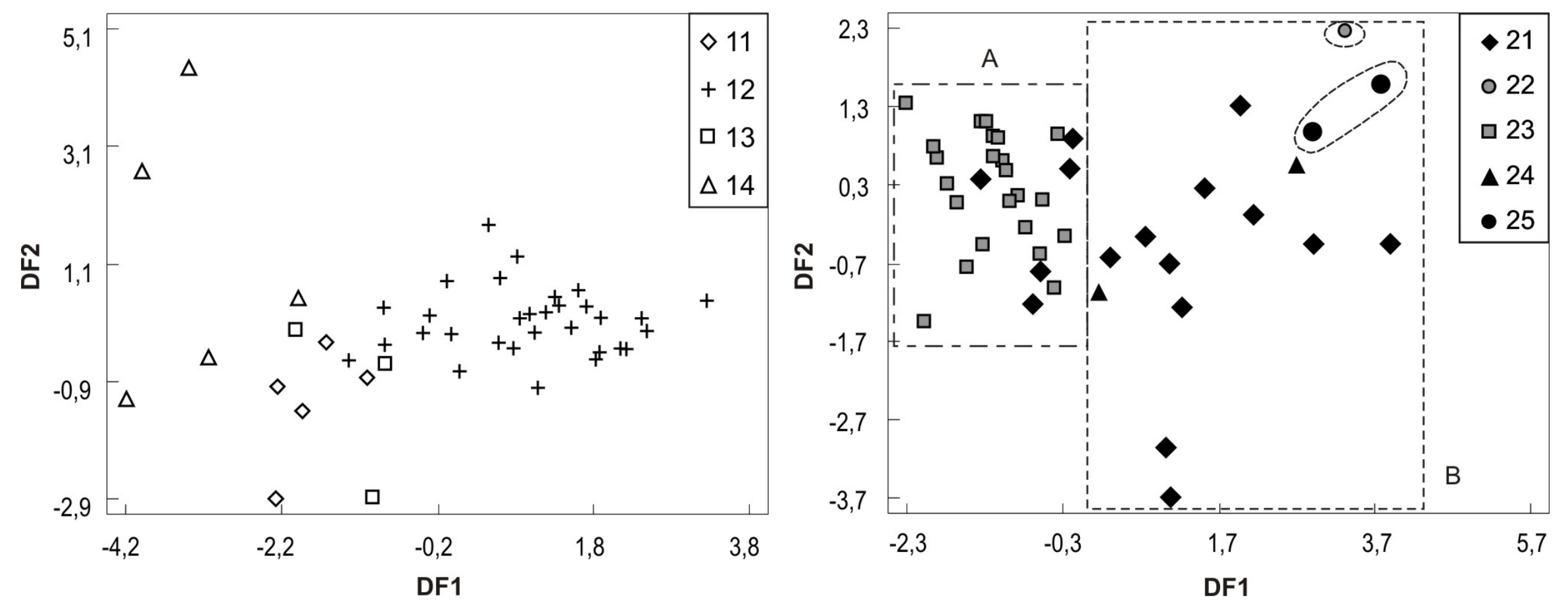

Figure 6 
TABLE 1. Lithological types (A) and hydrothermal alteration types (B) identified in the studied zone.

(A)
\begin{tabular}{|l|l|c|}
\multicolumn{1}{|c|}{ Classes } & \multicolumn{1}{|c|}{ Characteristics } & $\begin{array}{c}\text { Coded } \\
\text { values }\end{array}$ \\
\hline Porphyritic dykes & $\begin{array}{l}\text { Small and tabular bodies with andesitic } \\
\text { composition. Porphyritic to aphanitic texture with } \\
\text { plagioclase and occasionally amphibole } \\
\text { phenocrysts. }\end{array}$ & 11 \\
\hline $\begin{array}{l}\text { Porphyritic sub- } \\
\text { volcanic rocks }\end{array}$ & $\begin{array}{l}\text { Sub-volcanic intrusive body (stock). Porphyritic } \\
\text { texture with plagioclase and amphibole } \\
\text { phenocrysts. }\end{array}$ & 12 \\
\hline $\begin{array}{l}\text { Brecciated porphyritic } \\
\text { sub-volcanic rocks }\end{array}$ & $\begin{array}{l}\text { Brecciated texture sub-volcanic intrusive body } \\
\text { (stock). Brecciated and porphyritic texture with } \\
\text { plagioclase and amphibole phenocrysts. }\end{array}$ & 14 \\
\hline Volcanoclastic rocks & $\begin{array}{l}\text { Tuff, breccias and agglomerated sequences. } \\
\text { Homoclinal structure. }\end{array}$ & \\
\hline
\end{tabular}

(B)

\begin{tabular}{|c|c|c|}
\hline Alteration & Characteristics & $\begin{array}{l}\text { Coded } \\
\text { values }\end{array}$ \\
\hline Propylitic & $\begin{array}{l}\text { Chlorite (Chl), epidote (Ep), calcite (Cac) and } \\
\text { hematite (Hem) assemblages. }\end{array}$ & 21 \\
\hline Carbonatization & Calcite veins. & 22 \\
\hline Albitic & $\begin{array}{l}\text { Strong replacement of plagioclase by albite or } \\
\text { albite veins presence. }\end{array}$ & 23 \\
\hline Argillic assemblages & $\begin{array}{l}\text { Assemblages of undetermined clay minerals, Fe } \\
\text { oxy-hydroxide. This alteration is mainly related } \\
\text { with fault zones. }\end{array}$ & 24 \\
\hline Chloritic & $\begin{array}{l}\text { Veins and replacement of rock components by } \\
\text { chlorite. }\end{array}$ & 25 \\
\hline
\end{tabular}


TABLE 2. Analytes concentrations in the rock samples analysed

Code

Content of elements analyzed (expressed as $\mathrm{mg} / \mathrm{kg}$ )

\begin{tabular}{|c|c|c|c|c|c|c|c|c|c|c|c|c|}
\hline Sample & Rock & Alteration & Ca & $\mathrm{Cu}$ & $\mathbf{F e}$ & $\mathbf{K}$ & Mn & $\mathbf{P b}$ & $\mathbf{R b}$ & Sr & $\mathbf{T i}$ & Zn \\
\hline 2010 & 11 & 25 & 65394 & 90 & 59518 & 8918 & 1255 & $<$ l.o.d & 20 & 554 & 4698 & 77 \\
\hline 20104 & 12 & 22 & 62591 & 356 & 35454 & 11934 & 1508 & 31 & 38 & 396 & 1908 & 118 \\
\hline 2060 & 12 & 21 & 33347 & 20899 & 44028 & 17251 & 1509 & 146 & 48 & 372 & 1978 & $<$ l.o.d \\
\hline 2066 & 11 & 21 & 34559 & 376 & 63901 & 15345 & 1747 & 14 & 39 & 595 & 5742 & 79 \\
\hline 2098 & 12 & 23 & 30490 & 782 & 39927 & 19037 & 1789 & 26 & 52 & 327 & 2233 & 179 \\
\hline 3918 & 13 & 24 & 39603 & 130 & 45353 & 15216 & 1183 & 177 & 46 & 487 & 3015 & 94 \\
\hline 3980 & 13 & 21 & 36430 & 455 & 46006 & 8933 & 1149 & 57 & 23 & 362 & 2939 & 34 \\
\hline 41100 & 14 & 21 & 23879 & 10143 & 64067 & 17028 & 1800 & 60 & 85 & 410 & 3955 & 103 \\
\hline 4115 & 13 & 21 & 33144 & 798 & 46765 & 14652 & 1225 & 86 & 38 & 449 & 3251 & 109 \\
\hline 4141 & 14 & 21 & 33634 & 95 & 57738 & 17780 & 1253 & 40 & 52 & 608 & 4681 & 96 \\
\hline 4160 & 14 & 21 & 54627 & 271 & 42096 & 7456 & 1126 & 49 & 24 & 908 & 4727 & 78 \\
\hline 4161 & 14 & 21 & 43300 & 244 & 54505 & 12096 & 1389 & 34 & 34 & 704 & 5196 & 98 \\
\hline 4198 & 11 & 21 & 35326 & 649 & 60672 & 11675 & 1523 & 79 & 31 & 519 & 5320 & 84 \\
\hline 4199 & 14 & 21 & 24932 & 21193 & 74146 & 12254 & 2118 & 81 & 62 & 391 & 3011 & 182 \\
\hline 46145 & 12 & 23 & 30026 & 1109 & 39501 & 18823 & 1405 & 36 & 57 & 388 & 2249 & 125 \\
\hline 46146 & 12 & 23 & 28999 & 1372 & 36744 & 19900 & 1641 & 152 & 54 & 341 & 2239 & 132 \\
\hline 46147 & 12 & 23 & 31156 & 1342 & 42245 & 19365 & 2003 & 44 & 54 & 402 & 1970 & 147 \\
\hline 46148 & 12 & 23 & 29162 & 1457 & 43010 & 21714 & 1868 & 27 & 60 & 345 & 2124 & 135 \\
\hline 46149 & 12 & 23 & 27233 & 985 & 38604 & 20166 & 1475 & 14 & 59 & 321 & 2403 & 114 \\
\hline 46150 & 12 & 23 & 28988 & 741 & 33599 & 19807 & 1429 & 15 & 58 & 350 & 2071 & 135 \\
\hline 46151 & 12 & 21 & 29941 & 165 & 33961 & 19946 & 1395 & 20 & 56 & 384 & 2130 & 110 \\
\hline 46152 & 12 & 23 & 29218 & 478 & 37989 & 19713 & 1378 & 19 & 53 & 421 & 2083 & 92 \\
\hline 46153 & 12 & 23 & 28530 & 446 & 34185 & 18404 & 1381 & 21 & 49 & 405 & 2154 & 95 \\
\hline 46154 & 12 & 23 & 27669 & 1250 & 38656 & 18521 & 1600 & 24 & 51 & 388 & 2190 & 93 \\
\hline 46155 & 12 & 23 & 27794 & 1075 & 43310 & 20612 & 1598 & 18 & 58 & 406 & 2082 & 104 \\
\hline 46156 & 12 & 23 & 30885 & 1658 & 40289 & 19044 & 1568 & 29 & 45 & 420 & 2254 & 112 \\
\hline 46157 & 12 & 23 & 29943 & 876 & 33427 & 18759 & 1359 & 22 & 53 & 346 & 2121 & 106 \\
\hline 46158 & 12 & 23 & 27928 & 379 & 35874 & 17373 & 1203 & 21 & 46 & 331 & 2159 & 82 \\
\hline 46159 & 12 & 23 & 27100 & 348 & 33360 & 17850 & 1331 & 29 & 49 & 441 & 2100 & 75 \\
\hline 46160 & 12 & 23 & 26597 & 813 & 32892 & 21555 & 1292 & 19 & 59 & 577 & 1979 & 76 \\
\hline 46161 & 11 & 21 & 34623 & 203 & 42404 & 14304 & 1613 & 19 & 42 & 376 & 4617 & 131 \\
\hline 46162 & 12 & 23 & 30826 & 1960 & 37317 & 17308 & 1336 & 32 & 52 & 286 & 2299 & 110 \\
\hline 46163 & 12 & 23 & 31330 & 1244 & 37513 & 17092 & 1452 & 27 & 57 & 295 & 2151 & 86 \\
\hline 46164 & 12 & 23 & 28131 & 350 & 39190 & 20512 & 1606 & 50 & 60 & 342 & 2254 & 94 \\
\hline 46165 & 12 & 23 & 32414 & 2239 & 34170 & 17103 & 1216 & 22 & 47 & 320 & 2071 & 74 \\
\hline 46166 & 12 & 23 & 30772 & 2109 & 36361 & 17134 & 1464 & 36 & 53 & 394 & 2389 & 128 \\
\hline 46167 & 12 & 23 & 24912 & 978 & 37848 & 18888 & 1329 & 27 & 46 & 448 & 2017 & 68 \\
\hline 46168 & 12 & 23 & 29855 & 743 & 36164 & 16095 & 1251 & 24 & 41 & 402 & 1979 & 97 \\
\hline 46169 & 12 & 21 & 26345 & 525 & 40945 & 18021 & 1435 & 33 & 51 & 435 & 2064 & 102 \\
\hline 46171 & 12 & 21 & 25233 & 164 & 37103 & 19325 & 1103 & 30 & 54 & 422 & 2010 & 79 \\
\hline 46172 & 12 & 24 & 25949 & 274 & 36263 & 17169 & 1122 & 139 & 56 & 369 & 2155 & 105 \\
\hline 5844 & 12 & 21 & 36269 & 216919 & 43426 & 17828 & 1385 & 152 & 58 & 411 & 1963 & $<$ l.o.d \\
\hline 5860 & 11 & 25 & 49599 & 108 & 51867 & 13772 & 1266 & 19 & 31 & 678 & 4819 & 67 \\
\hline 5861 & 12 & 21 & 47808 & 514 & 58262 & 14273 & 2177 & 92 & 40 & 444 & 5686 & 161 \\
\hline
\end{tabular}


TABLE 3. Standardized coefficients of Weights of Box-Cox transformed variables in Principal Component and Factorial analysis functions.

\begin{tabular}{|c|c|c|c|c|c|c|}
\hline \multirow[t]{2}{*}{ Variables } & \multicolumn{3}{|c|}{ Principal Components } & \multicolumn{3}{|c|}{ Varimax rotated Varifactors } \\
\hline & PC1 & $\underline{\text { PC2 }}$ & $\underline{\text { PC3 }}$ & $\underline{\text { VF1 }}$ & $\underline{\mathrm{VF} 2}$ & $\underline{\text { VF3 }}$ \\
\hline WCa & 0.4 & $0.0_{2}$ & -0.1 & 0.4 & $0.0_{2}$ & -0.1 \\
\hline WCu & -0.3 & 0.3 & 0.4 & -0.3 & 0.3 & 0.4 \\
\hline WFe & 0.3 & 0.5 & $0.0_{5}$ & 0.3 & 0.5 & $0.0_{5}$ \\
\hline WK & -0.4 & -0.1 & -0.2 & -0.4 & -0.1 & -0.2 \\
\hline WMn & -0.2 & 0.6 & -0.2 & -0.2 & 0.6 & -0.2 \\
\hline WPb & $0.0_{4}$ & 0.3 & 0.7 & $0.0_{4}$ & 0.3 & 0.7 \\
\hline WRb & -0.4 & 0.2 & $-0.0_{1}$ & -0.4 & 0.2 & $-0.0_{1}$ \\
\hline WSr & 0.3 & $0.0_{2}$ & -0.1 & 0.3 & $0.0_{2}$ & -0.1 \\
\hline WTi & 0.4 & 0.3 & -0.1 & 0.4 & $0.3^{2}$ & -0.1 \\
\hline WZn & -0.2 & 0.4 & -0.4 & -0.2 & 0.4 & -0.4 \\
\hline
\end{tabular}


TABLE 4. DLA classifications obtained for the rock samples analysed.

(a) Criteria: Lithology of the samples

$\underline{\text { Classes }} \quad \underline{\text { Code }} \underline{\text { Samples }} \quad \underline{\text { Predicted }}$

\begin{tabular}{|c|c|c|c|c|c|c|}
\hline & & & $\underline{11}$ & $\underline{12}$ & $\underline{13}$ & $\underline{14}$ \\
\hline Porphyritic dykes & 11 & 5 & $\begin{array}{c}0 \\
(0.00 \%)\end{array}$ & $\begin{array}{c}5 \\
(100 \%)\end{array}$ & $\begin{array}{c}0 \\
(0.00 \%)\end{array}$ & $\begin{array}{c}0 \\
(0.00 \%)\end{array}$ \\
\hline $\begin{array}{l}\text { Porphyritic sub- } \\
\text { volcanic rocks }\end{array}$ & 12 & 31 & $\begin{array}{c}0 \\
(0.00 \%)\end{array}$ & $\begin{array}{c}31 \\
(100 \%)\end{array}$ & $\begin{array}{c}0 \\
(0.00 \%)\end{array}$ & $\begin{array}{c}0 \\
(0.00 \%)\end{array}$ \\
\hline $\begin{array}{l}\text { Brecciated porphyritic } \\
\text { sub-volcanic rocks }\end{array}$ & 13 & 3 & $\begin{array}{c}0 \\
(0.00 \%)\end{array}$ & $\begin{array}{c}3 \\
(100 \%)\end{array}$ & $\begin{array}{c}0 \\
(0.00 \%)\end{array}$ & $\begin{array}{c}0 \\
(0.00 \%)\end{array}$ \\
\hline Volcanoclastic rocks & 14 & 5 & $\begin{array}{c}0 \\
(0.00 \%)\end{array}$ & $\begin{array}{c}5 \\
(100 \%)\end{array}$ & $\begin{array}{c}0 \\
(0.00 \%)\end{array}$ & $\begin{array}{c}0 \\
(0.00 \%)\end{array}$ \\
\hline
\end{tabular}

\section{(b) Criteria: Alteration types}

\begin{tabular}{|c|c|c|c|c|c|c|c|}
\hline$\underline{\text { Alteration }}$ & $\underline{\text { Code }}$ & $\underline{\text { Samples }}$ & & & Predicted & & \\
\hline & & & $\underline{21}$ & $\underline{22}$ & $\underline{23}$ & $\underline{24}$ & $\underline{25}$ \\
\hline Propylitic & 21 & 16 & $\begin{array}{c}6 \\
(37.50 \%)\end{array}$ & $\begin{array}{c}1 \\
(6.25 \%)\end{array}$ & $\begin{array}{c}3 \\
(18.75 \%)\end{array}$ & $\begin{array}{c}4 \\
(25 \%)\end{array}$ & $\begin{array}{c}2 \\
(12.50 \%)\end{array}$ \\
\hline Carbonatization & 22 & 1 & $\begin{array}{c}0 \\
(0.00 \%)\end{array}$ & $\begin{array}{c}1 \\
(100 \%)\end{array}$ & $\begin{array}{c}0 \\
(0.00 \%)\end{array}$ & $\begin{array}{c}0 \\
(0.00 \%)\end{array}$ & $\begin{array}{c}0 \\
(0.00 \%)\end{array}$ \\
\hline Albitic & 23 & 23 & $\begin{array}{c}1 \\
(4.35 \%)\end{array}$ & $\begin{array}{c}0 \\
(0.00 \%)\end{array}$ & $\begin{array}{c}22 \\
(95.65 \%)\end{array}$ & $\begin{array}{c}0 \\
(0.00 \%)\end{array}$ & $\begin{array}{c}0 \\
(0.00 \%)\end{array}$ \\
\hline $\begin{array}{c}\text { Argillic } \\
\text { assemblages }\end{array}$ & 24 & 2 & $\begin{array}{c}0 \\
(0.00 \%)\end{array}$ & $\begin{array}{c}0 \\
(0.00 \%)\end{array}$ & $\begin{array}{c}0 \\
(0.00 \%)\end{array}$ & $\begin{array}{c}2 \\
(100 \%)\end{array}$ & $\begin{array}{c}0 \\
(0.00 \%)\end{array}$ \\
\hline Chloritic & 25 & 2 & $\begin{array}{c}0 \\
(0.00 \%)\end{array}$ & $\begin{array}{c}0 \\
(0.00 \%)\end{array}$ & $\begin{array}{c}0 \\
(0.00 \%)\end{array}$ & $\begin{array}{c}0 \\
(0.00 \%)\end{array}$ & $\begin{array}{c}2 \\
(100 \%)\end{array}$ \\
\hline
\end{tabular}

